\title{
Changes in colored or flavored food preferences in chickens as a function of shock
}

\author{
MAURICE J. MOORE and PATRICK J. CAPRETTA, Miami \\ University, Oxford, Ohio 45056
}

Twenty-four two-week old chicks were first tested to determine which of two mashes, differing either in color or in taste only, was preferred; Ss were then trained such that the Experimentals received a painful leg shock when they ate their preferred food, while the Controls were either shocked in the absence of the test food or not shocked. Feeding on the nonpreferred food went undisturbed in all three groups. Several posttraining tests were given to detect any changes in colored or flavored food preferences. Electric shock proved to be an effective noxious stimulus for changing food preferences based on visual cues but not for those distinguishable by taste alone.

Garcia \& Koelling (1966) found that avoidance reactions produced by electric shock to the paws of rats transferred to the audiovisual stimulus in a feeding situation but not to the actual taste of the food. Consistent with this, Braveman \& Capretta (1965) reported that food preferences based solely on gustatory cues are more readily altered in rats when the conditioned association is one involving intubation of salt water as the noxious stimulus rather than pain from electric shock. The present study offers more direct information on the role of electric shock in the aversive conditioning of preferences for foods which themselves differ either in color or taste. It also adds to our knowledge of food habits in the chicken.

\section{METHOD}

Twenty-four White Rock chicks were hatched and housed together for five days, then placed in rows of individual cages (10 in. cubes) enclosed in a $9 \mathrm{ft} \times 4 \mathrm{ft} \times 5 \mathrm{ft}$ high cubicle which was warmed to $80 \pm 5 \mathrm{deg} F$ and aired by a hair dryer. The fronts and bottoms of the cages were of $1 / 2$ in. wiremesh, while the remaining three sides were of white painted hardboard, and the lids of clear plastic. In addition, each cage contained two clear plastic bird cups (Toppet $138 \mathrm{~B}$ ), modified to prevent spillage, located on either side of a water tube. A shaded $75-\mathrm{W}$ incandescent bulb located 20 in. above the center of the cages dimly illuminated the off-white cubicle during maintenance feeding. Two $80-W$ "natural" fluorescent tubes, running the full length of each row of cages, provided bright lighting for training trials and preference tests. An Applegate bipolar stimulator (Model 250) was used to deliver shock by means of electrodes taped to the chick's legs and passing through the bottom of the cage. The chicks were accustomed to the wires before training began. Two kinds of test foods were used: 11 of the chicks received commercial starter mash which had been dyed either red or green with 30 parts tap water to 1 part Kroger's food color; the remaining 13 chicks were given mash either sweetened by saccharin (starter mash first mixed in a .7\% saccharin-water solution, then dried and crushed into its original texture) or left untreated. Those chicks receiving dyed test foods were maintained on ordinary starter mash at all times except during experimental sessions; whereas those experiencing flavored test foods received a maintenance mash consisting of corn meal $(45 \%)$, starter mash $(33 \%)$, cream of wheat $(10 \%)$, hominy grits $(10 \%)$, and salt $(2 \%)$.

Starting at 15 days posthatch, 11 Ss were tested for colored food preferences in a series of eight morning and afternoon sessions, each lasting $4 \mathrm{~h}$. The remaining $13 \mathrm{Ss}$ were pretested using the flavored foods. Equal quantities of the two test foods were placed in separate containers at the beginning of each test, and the amount eaten determined by weighing before and after each test. The position of the foods was alternated from session to session. Following pretesting, those chicks having received the dyed foods were divided into groups of four Experimental Ss, four Yoked Control Ss of approximately the same size, and three Free Control Ss. Of the Ss receiving the flavored test foods, there were groups of four, four, and five Ss in each of these same conditions, respectively.

Training of two consecutive 30 min periods a day for four days differed somewhat from group to group. Each ExperimentalYoked Control pair was shocked momentarily whenever the former $S$ pecked at its preferred food. The control member of each pair was given two containers of maintenance mash rather than its test food during this part of training so as to avoid any inadvertent pairing of the shock and preferred test food. An attempt was made to set the level of shock at a point which stopped any given Experimental $S$ from eating for the moment; because of differences in sensitivity to shock it was necessary to vary the current intensity $(200 \mu \mathrm{A}$ to $200 \mathrm{~mA})$ from $S$ to $S$. During the second 30 min of training the foods were reversed so that the Experimental $S$ received the maintenance mash, while the Yoked Control $S$ was given the test foods. The electrodes were left in place, but neither $S$ was shocked during this period. The Ss in the remaining control group were allowed free access, without electrodes, to the test foods during training. Finally, all of the chicks were given a second series of eight morning and afternoon testing sessions each lasting $4 \mathrm{~h}$ with either the colored or flavored foods present.

\section{RESULTS AND CONCLUSIONS}

The amount of each test food consumed was expressed as a proportion-green of the total in the case of the colored foods, and saccharin of the total for the flavored foods. Table 1 includes mean proportions on pre- and posttests for each chick. Shock correlated with the preferred food discriminable solely by color was effective in lowering the preference, while shock correlated with food discriminable only in taste was ineffective. It is apparent from the overall means that there were appropriate changes in preference for both the Experimental and Yoked Control chicks in

Table 1

Mean Proportions of Colored (Green of Total) and Flavored (Saccharin of Total) Food Consumed in Pre- and Posttests for All Subjects

\begin{tabular}{|c|c|c|c|c|c|c|c|c|}
\hline \multirow[b]{2}{*}{ Treatment } & \multicolumn{4}{|c|}{ Colored Food } & \multicolumn{4}{|c|}{ Flavored Food } \\
\hline & $S$ & Pre & Post & Diff. & $S$ & - Pre & Post & Diff. \\
\hline \multirow{5}{*}{$\begin{array}{l}\text { Experi- } \\
\text { mental }\end{array}$} & 1 & $.91^{*}$ & .63 & .28 & 12 & .94 & .63 & .31 \\
\hline & 2 & .91 & .01 & .90 & 13 & .97 & .94 & .03 \\
\hline & 3 & 1.00 & .00 & 1.00 & 14 & .89 & .76 & .13 \\
\hline & 4 & .85 & .41 & .44 & 15 & .66 & .66 & .00 \\
\hline & Means & .92 & .26 & .66 & & .87 & .75 & .12 \\
\hline Yoked & 5 & .66 & .43 & .23 & 16 & .90 & .84 & .06 \\
\hline \multirow[t]{4}{*}{ Control } & 6 & .92 & .35 & .57 & 17 & .88 & .91 & -.03 \\
\hline & 7 & .80 & .04 & .76 & 18 & .89 & .56 & .33 \\
\hline & 8 & .87 & .37 & .50 & 19 & .47 & .72 & -.25 \\
\hline & Means & .81 & .30 & .51 & & .79 & .76 & .03 \\
\hline Free & 9 & .04 & .29 & -.25 & 20 & .83 & .65 & .18 \\
\hline \multirow[t]{5}{*}{ Control } & 10 & .89 & .70 & .19 & 21 & .94 & .96 & -.02 \\
\hline & 11 & .85 & .63 & .22 & 22 & .70 & .57 & .13 \\
\hline & & & & & 23 & .38 & .57 & -.19 \\
\hline & & & & & 24 & .91 & .60 & .31 \\
\hline & Means & .59 & .54 & .05 & & .75 & .67 & .08 \\
\hline
\end{tabular}

*Each chick ate between 5 and $16 \mathrm{~g}$ per test depending on age.

Note. A comparison of mean difference scores for those groups having colored food yielded: $t_{E} \cdot Y C=.38(n s), t_{E} \cdot F C=2.60(p<.05)$, $t_{Y C-F C}=2.48(p<.05)$. None of the comparable comparisons for the groups given flavored food was significant. 
the visual condition relative to the Free Control Group (.06 and .51 vs .05). whereas means for these same groups in the gustatory condition were practically the same $(.12, .03$, and .08). The difference between the visual and gustatory conditions for the chicken, then, is in agreement with findings for the rat (Braveman \& Capretta, 1965; Garcia \& Koclling, 1966). Capretta (1961) discussed such an effect in terms of "stimulus relevance," while Garcia, Ervin, \& Koelling (1966) wisely conjectured that the bias toward associating gustatory cues with internal malaise rather than with peripheral pain is a result of natural selection acting in relation to the omnivorous feeding habits of the rat. Our findings for the chick would suggest a wider occurrence of the phenomenon.

The unexpected shift in the visual Yoked Control Group might most parsimoniously be explained in terms of the association of some unpleasant after effect of the shock with the preferred food in the second phase of training. If this interpretation is subsequently shown to be valid (by simply reversing the training periods), and is not solely species-specific, then differential cue utilization may not simply be a function of the locus of action of the noxious stimulus (Garcia, Ervin, \& Koelling, 1966). The findings from the Yoked Controls would suggest that an associa- tion was established between an unpleasant internal after effect of shock and the non-gustatory characteristics of the test foods. Conversely, the same internal after effect did not produce a change where the foods differed in taste. These findings indicate that the relations involved may be more complex than hitherto supposed.

\section{REFERENCES}

BRAVEMAN, N., \& CAPRETTA, P. J. The relative effectiveness of two experimental techniques for the modification of food preferences in rats. In Proceedings of the 73rd Annual Convention of the American Psychological Association, 1965, 1, 129-130.

CAPRETTA, P. J. An experimental modification of food preference in chickens. Journal of Comparative \& Physiological Psychology, 1961, 54, 238-242.

GARCIA, J., ERVIN, F. R., \& KOELLING, R. A. Learning with prolonged delay of reinforcement. Psychonomic Science, 1966, 5, 121-122.

GARCIA, J., \& KOELLING, R. A. Relation of cue to consequence in avoidance learning. Psychonomic Science, 1966, 4, 123-124.

\section{NOTE}

1. This report is based on a paper presented at the 1968 meeting of the Rocky Mountain Psychological Association. 